of dawn rattles in night's dry throat, glitters with the leaden polar cross.

By incomplete by light by love she is a naked girl facing the mirror lifting her hair high above her neck to pin, her shadeless skin all mortal.

The angel hasn't filled the day's labyrinth with thunder. The green planet roars and the blue thrush circles her arms in feathered rings.

By love incomplete and light the travellers escape through a large valley with heads bared to the clouds: a black pinion cuts a brown galaxy of grass.

By love by incomplete by bright world structure dream: let the years and valleys be open.

Translated by the author and Jerzy Przezdziecki with Burt Blume

\title{
The Poet Establishes the Height of the Building
}

This is such a tall building that you can see the Hudson and the East River all the way round, though you can't read the names of the freighters neither can you figure out whom or what they are carrying.

It is so tall

that on top of it even the foreigner is filled with a vicarious pride, 
but not so tall that it can hide us from the mushrooms and other products of the atomic kitchen.

It is taller than the Tikal pyramids, taller than those of the Moon and of the Sun in Teotihuacan, taller than the cruelty of Assurbanipal, but not tall enough for us to see the watermen of San Francisco wasting away on their own shores.

This building is very tall, taller than sequoias, though some of them have been stretching upwards for two thousand years, taller than any of the hills around my childhood, tall as schoolroom Himalayas

but not as tall as the leap of its early suicides.

It is as tall

as the flame of the self-immolating Buddhist, as tall

as the eyes of the girl from Oklahoma, as tall as the shots of the Cananeia ambush.

But the tunnelings of the guerrilla are even taller and the planes which fly napalm fly no higher than its elevators.

This building is very tall.

So tall that I can see the streets I came through though I can't see who is profiting or losing in the corridors of Wall Street. I hear my girl, her accent is German.

Auschwitz is not visible.

There is no question that this building is the tallest. Tallest in the world, maybe, the tallest-maybe in the world, the tallest in the maybe-world, this building is a concrete-maybe, the most concrete, maybe, in the world, the concrete world the world more or less maybe this is the building of buildings, 
the best built building

the buildingest building

built builter builtest

buildingissimus.

Translated by the author

STEWART YUEN / HONG KONG

\section{The Faceless Man}

It seemed to be morning

I walked to the mirror and saw

my feet in British boots

my legs in U.S. Levis

my neck with an Italian scarf

my waist with a Spanish belt

my head with a French cap

But the face beneath it was missing

Totally faceless, I don't know

whether I was crying or laughing

sad or angry

So I've realized

that there has never been a Stewart Yuen

there never was

there never will be

And now in the mirror

as the colors of these nations clash

I lose even my shadow

Translated by William Tay 